ROBERT RIJAVEC, M.Sc. ${ }^{1}$

E-mail: robert.rijavec@fgg.uni-lj.si

DARJA ŠEMROV, Ph.D. ${ }^{1}$

E-mail: darja.semrov@fgg.uni-lj.si

${ }^{1}$ University of Ljubljana,

Faculty of Civil and Geodetic Engineering

Jamova 2, 1000 Ljubljana, Slovenia
Traffic on Motorways

Preliminary Communication

Submitted: 20 Apr. 2017

Accepted: 28 Nov. 2017

\title{
EFFECTS OF WEATHER CONDITIONS ON MOTORWAY LANE FLOW DISTRIBUTIONS
}

\begin{abstract}
Several factors affect the lane choices made by motorway drivers. According to the driving rules, the nearside lane is the one that is primarily used. The main reasons for lane changes are overtaking, congestion, or restrictions on other lanes. The empirical research presented in this paper presents comprehensive traffic characteristics observed in different traffic lanes on four-lane motorways in Slovenia. The research was focused on the influence of adverse weather conditions on the lane flow distribution, and on the speed of vehicles in different lanes. The lane flow and speed distributions both directly affect road capacity and safety; therefore, estimating these characteristics could improve the reliability of active traffic control when traffic flow perturbation is detected. Field test results show that lane flow distributions and lane speed distributions at a particular site vary depending on weather conditions, namely, dry, wet (rain), low-visibility, and snow conditions.
\end{abstract}

\section{KEY WORDS}

motorway traffic control; lane flow distribution; lane speed distribution; weather conditions;

\section{INTRODUCTION}

Road characteristics, traffic demands, maintenance work, adverse weather conditions, accidents, and other unpredictable incidents influence the traffic flow characteristics of motorway lanes [1]. In the case of maintenance work or road accidents, the number of available lanes is usually reduced, and vehicles are redistributed to other (available) lanes. Rain, snow, fog, or other weather occurrences that reduce visibility and vehicle stability generally do not affect the number of available lanes, but do affect the driving dynamics and reduce lane capacity utilisation $[2,3]$. On the other hand, traffic demand is also affected by adequate traffic and travel information, including traffic and weather forecasts $[4,5]$.

On motorway sections with real-time traffic control system (particularly where dynamic lane control has been introduced) drivers obey to some extent various message signs. Dynamic speed limits affect lane flows and speed distributions, resulting in improved capac- ity utilisation [6]. Traffic control technology is not the scope of this paper, but it should be noted that in the future this technology will be significant since intelligent speed adaptation systems in vehicles, or autonomous vehicles, will perform better than human drivers [7].

Generally, drivers change traffic lanes because of differential speeds (i.e., overtaking) or because of obstacles in the current lane [8]. Some drivers do not change lanes because of so-called 'lane-hogging' behaviour [9]. Driver behaviour can be described by traffic lane-changing models [10]. Empirical models discussed in [11] are based on a Daganzo traffic-behaviour model [12]. Studies have already proved the mathematical approach based on the gap-acceptance theory to be too complex for practical use; therefore, a regression equation has been proposed for linking lane flow distributions under arbitrary traffic conditions and traffic demands [13, 14].

The influence of weather and environment on traffic characteristics has been widely researched, particularly with respect to the type and intensity of rain and snowfall, temperatures, and visibility. The results of several studies can be summarised as follows: in free flow conditions and low intensity rain the vehicle speed drops by up to $5 \%$, in medium rain up to $10 \%$, in heavy rain up to $15 \%$, in reduced visibility between $5 \%$ and $15 \%$, in low intensity snowfall up to $5 \%$, and in heavy snowfall by up to $30 \%$ Capacity utilisation in adverse weather conditions decreases parallel with the speed [3, 15-19]. A wide range of traffic characteristics can be explained by the influence of not only weather, but also location and driver behaviour in different situations. No studies were conducted to determine differences in lane flow and speed distributions on multi-lane motorways, which has been recognised as a traffic characteristic that can explain the relation between traffic flow conditions and safety [20]. The coefficient of speed variation (CVS) and minimum average gap can be interpreted as predictors of unstable traffic conditions and potential crash occurrence. 
Crash potential increases with higher levels of speed variation, smaller gap between vehicles, and exposure $[21,22]$.

On motorway sections a traffic control system is often set up to ensure higher levels of service and safety. One of the functions of the traffic control system is traffic lane control, which uses different control strategies to restrict speed and to manage lane movement in response to different traffic situations, different weather conditions, and safety issues such as incidents and accidents [23]. With better knowledge of lane flow distributions in adverse weather conditions, it is possible to introduce additional criteria for lane and speed control, before unstable traffic flow occurs [24].

\section{ISSUES AND BASIC HYPOTHESES}

Density and heterogeneity of traffic flow, speed limits and desired speeds in association with road geometry characterise lane flow distribution. Lane flow distribution can be expressed as the traffic flow rate on a specific traffic lane or the proportion of the total directional traffic flow on the traffic lane. The lane speed distribution can be expressed as distribution of CVS defined as the ratio of the standard deviation to the mean lane speed of the traffic flow.

It can be assumed that different weather conditions influence the lane flow and speed distribution on motorway carriageways; generally, we could refer to this as lane capacity utilisation. The obtained data on the lane flow and speed distribution can be used for the recognition of flow stability, congestion, and other potentially dangerous situations. Recent studies of the traffic flow distribution have reported different results. Studies commonly neglect the weather conditions; therefore, the hypothesis that traffic characteristics on particular traffic lanes vary depending on weather conditions is rising. It is assumed that due to weather conditions, the lane flow distributions at the observed road section change, and due to reduced visibility (fog, rain or snow) the dispersion of the coefficient of speed variation is different than in normal visibility and dry conditions.

\section{EXPERIMENT}

Our research was conducted for two four-lane motorway sections near Ljubljana, Slovenia (see Figure 1), with AADT 64,050 and 68,587 , and $9 \%$ and $6 \%$ of heavy vehicles, respectively; on the first analysed motorway section, hereinafter referred to as "test site 178 ", where speed limit is $130 \mathrm{~km} / \mathrm{h}$, and on the second, hereinafter referred to as "test site 855", where speed limit is $100 \mathrm{~km} / \mathrm{h}$. Accurate weather data for the analysed period were collected from a nearby weather station (GPS $46^{\circ} 02^{\prime} 14^{\prime \prime} \mathrm{N}, 14^{\circ} 27^{\prime} 04^{\prime \prime} \mathrm{E}$ ).

Traffic and weather data have been acquired every 5 minutes. Therefore, a common database was created using timestamp reference keys. The traffic data set include information on traffic volume by vehicle classes, time mean speed, average time clearances between vehicles (average gap) and the occupancy of loop sensors on different traffic lanes. Traffic data were analysed for several weather conditions: dry, wet (rainy), low visibility, and snowy. Dry conditions are understood as a dry pavement conditions, with good visibility and without precipitation. For wet (rainy) conditions, three rainfall intensity classes were defined: low $(0.8-6 \mathrm{~mm} / \mathrm{h})$, medium $(6-15 \mathrm{~mm} / \mathrm{h})$, and heavy (more than $15 \mathrm{~mm} / \mathrm{h}$ ) [25]. Low visibility conditions due to both fog and precipitation, with visibility lower than $250 \mathrm{~m}$, were analysed. Analysing the impact of snow conditions on traffic flows, two factors were taken into account, namely, type of precipitation (light, moderate, and heavy snow) and type of road surface (slush, melted snow, ice). Records obtained for intermediate conditions (e.g. no precipitation but wet pavement), extreme traffic flows, and incident conditions (e.g. vacation periods and roadwork) were filtered out. Only the data meeting the following conditions were
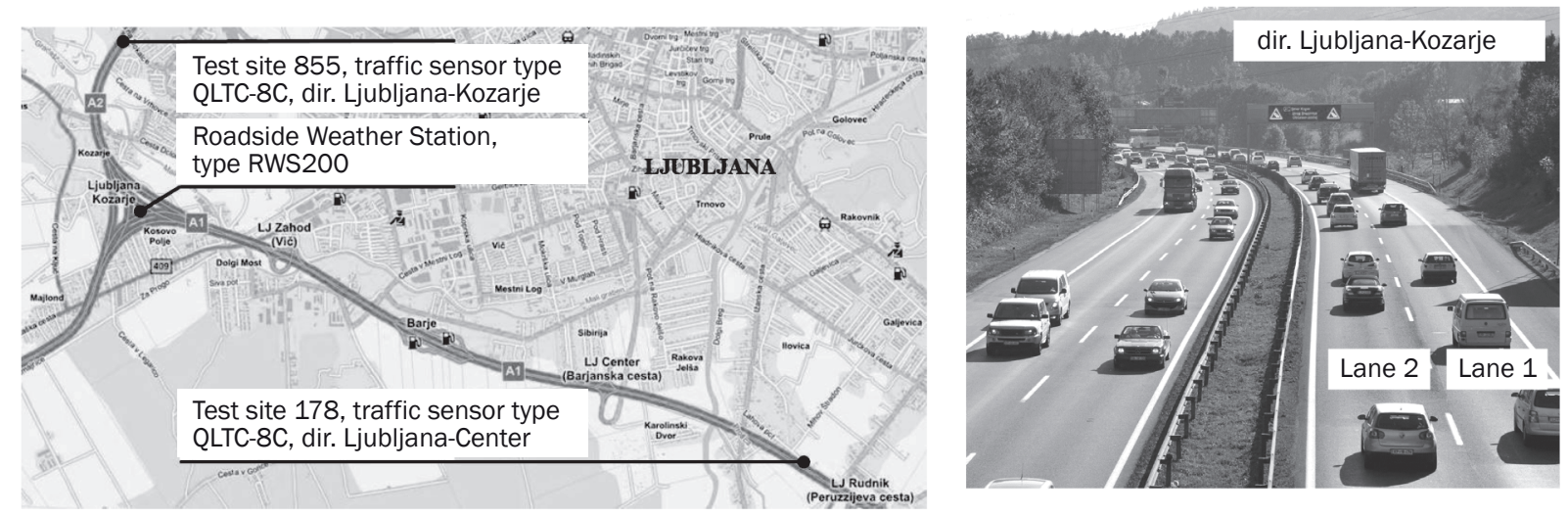

Figure 1 - Locations of test sites on motorway network near Ljubljana and lane positions at test site 855 
considered: time mean speed between 60 and 160 $\mathrm{km} / \mathrm{h}$, an average gap between 1 and $30 \mathrm{~s}$, and a 5-minute traffic volume greater than 3 vehicles.

In total, 18,306 five-minute intervals were analysed from October 2012 to February 2013; namely, 13,267 in dry conditions, 3,469 in low rainfall intensity conditions, 444 in medium rainfall intensity conditions, 83 in heavy rain conditions, 867 in low visibility conditions, and 159 in snowy conditions. Usually, traffic demand in low visibility weather conditions, especially in heavy snow, is lower than in normal conditions [26]; therefore, the size of the sample is smaller but the adequacy of the results was not affected.

\subsection{Analysis}

The analysis of the lane flow distributions and traffic characteristics is based on the assumptions made in previous studies. The lane flow distribution $p_{i, k}$ is a function of traffic demand flow in one direction, $q_{t o t, k}$. In our research, several additional weather conditions $(k)$ were investigated; namely, dry $\left(\_d\right)$, rain and wet $(w 1, w 2, w 3)$, low visibility $\left(\_l v\right)$, and snow $\left(\_s\right)$. Heavy vehicles have been taken into account by including the heavy vehicle adjustment factor $f_{H V, i, k}$, determined in accordance with the Highway Capacity Manual's (HCM) methodology [1]. The total equivalent flow rate $q_{\text {tot }, k}$ (observed traffic demand flow) in one direction can be calculated as:

$$
\begin{aligned}
q_{t o t, k} & =\sum_{i=1}^{n=2} q_{e, i, k}=\sum_{i=1}^{n=2} \frac{q_{i, k}}{f_{H V, i, k}} \\
f_{H V, i, k} & =\frac{1}{1+P_{T, i, k}\left(E_{T}-1\right)+P_{R, i, k}\left(E_{R}-1\right)}
\end{aligned}
$$

where $q_{i, k}$ is the 5-minute flow rate for lane $i$ expressed in vehicles per hour, and $q_{e, i, k}$ is expressed in passenger-car units per hour; $P_{T, i, k}$, and $P_{R, i, k}$ are the proportions of heavy and recreational vehicles; and $E_{T}$ and $E_{R}$ are passenger-car equivalents for heavy and recreational vehicles, respectively. Our research was conducted on level terrain, and traffic data neglect recreational vehicles $\left(P_{R, i, k}=0\right)$. For all weather conditions, the parameter $E_{T}$ is set to 1.5 . As the test site was set up on a four-lane motorway, two lane positions $i$ have been considered; namely, lane $i=1$ as the nearside traffic lane and lane $i=2$ as the offside (overtaking) traffic lane (Figure 1).

The lane flow distribution $p_{i, k}$ for $i=1,2$ under $k$ weather conditions can be calculated as follows:

$$
\left\{\begin{array}{l}
p_{1, k}=\frac{q_{e, 1, k}}{q_{t o t, k}} \\
p_{2, k}=\frac{q_{e, 2, k}}{q_{t o t, k}}=1-p_{1, k}
\end{array}\right.
$$

where $q_{t o t, k}$ is the total flow rate for all lanes; $p_{1, k}$ and $p_{2, k}$ are the proportions of the total flow rate under $k$ various weather conditions for Lane 1 and Lane 2.
A single function enables the direct comparison of lane flow distribution (4). For two-lane carriageways, the lane flow distribution characteristics can be expressed as [27]:

$$
d p_{k}\left(q_{t o t, k}\right)=p_{1, k}-p_{2, k}
$$

To calculate and analyse the local density $d_{i, k}$ under $k$ weather conditions on lane $i$, the equivalent flow rate $q_{e, i, k}$ is divided by space mean speed $v_{s, i, k}$ (if $v_{s, i, k} \neq 0$ ). However, the data contain only the time mean speed $v_{t, i, k}$. The space mean speed is estimated by using Drake's formula [28].

The coefficient of speed variation for lane $i$ is defined as follows:

$$
C V S_{i, k}=\frac{S D_{i, k}}{v_{t, i, k}}
$$

where $S D_{i, k}$ is the standard deviation of speed at 5-minute intervals and $v_{t, i, k}$ is the average speed over the same interval under $k$ weather conditions on lane $i$.

\section{RESULTS}

The research of impact of weather on lane flow distribution, time mean speed of vehicles, and gap between vehicles was examined on two test sites; namely, two motorway sections in Slovenia. Since the aim of research is to investigate the impact of adverse weather conditions and comparison of the traffic flow characteristics in adverse weather conditions with the traffic flow characteristics in dry condition, the data obtained in congested traffic flow and in time of incident situations have been discharged.

\subsection{Lane position and main traffic characteristics under different weather conditions}

This section summarizes the main traffic characteristics under different weather conditions at test site 178. The descriptive statistics results are presented in Table 1. The results show statistically significant differences between the mean values of different traffic characteristics for the two-lane positions for all weather conditions. The mean values of equivalent flow rates and traffic flow densities are higher for Lane 1 than Lane 2 in dry conditions, while the mean values of time mean speed are lower. These differences are expected, but the relative differences of traffic characteristics (Table 1, $\mu_{1, k}-\mu_{2, k}$ ) between Lane 1 and Lane 2 had not been foreseen.

The differences in mean values of time mean speed decrease with adverse weather conditions from $10 \%$ to $16 \%$ (18\% for dry condition), while for equivalent flow rates and density, they increase; the differences of flow rates from $35 \%$ to $116 \%$ (26\% for dry conditions), and differences of density from $67 \%$ to $163 \%$ (59\% for dry conditions). Comparing traffic characteristics, the 
Rijavec R, Šemrov D. Effects of Weather Conditions on Motorway Lane Flow Distributions

Table 1 - Descriptive statistics of main traffic characteristics and paired difference results for test site 178

\begin{tabular}{|c|c|c|c|c|c|c|c|c|c|c|c|}
\hline \multirow{2}{*}{ Var. } & \multirow{2}{*}{ Unit } & \multirow{2}{*}{ Min } & \multirow{2}{*}{ Max } & \multirow{2}{*}{$\begin{array}{c}\text { Mean } \\
\mu_{i, k}\end{array}$} & \multirow{2}{*}{$\begin{array}{l}\text { Std. } \\
\text { dev. }\end{array}$} & \multirow{2}{*}{$\begin{array}{l}\text { Rel. diff. } \\
\left(\mu_{i, d}-\mu_{i, k}\right)\end{array}$} & \multirow{2}{*}{$\begin{array}{l}\text { Rel. diff. } \\
\left(\mu_{1, k}-\mu_{2, k}\right)\end{array}$} & \multicolumn{4}{|c|}{$\begin{array}{l}\text { Two-sample t-test. } \\
\text { Hypothesis: } \mu_{1, k}-\mu_{2, k}<>0\end{array}$} \\
\hline & & & & & & & & $\mu_{1, k} \mu_{2, k}$ & $\mathrm{~T}$ & $d f$ & $\begin{array}{c}\text { Sig. } \\
\text { (2-tailed) }\end{array}$ \\
\hline$q_{e, 1, d}$ & \multirow{12}{*}{ 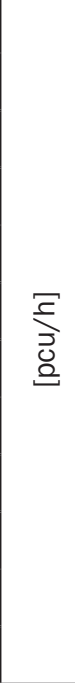 } & 53 & 1,709 & 812.2 & 396.8 & - & & & & & \\
\hline$q_{e, 2, d}$ & & 0 & 2,675 & 646.6 & 511.3 & - & $26 \%$ & 165.6 & 89.4 & 13,266 & 0 \\
\hline$q_{e, 1, w 1}$ & & 51 & 1,606 & 696.0 & 370.4 & $-14 \%$ & & & & & \\
\hline$q_{e, 2, w 1}$ & & 0 & 2,649 & 515.0 & 491.2 & $-20 \%$ & $35 \%$ & 181.0 & 48.7 & 3468 & 0 \\
\hline$q_{e, 1, w 2}$ & & 93 & 1,711 & 674.5 & 385.6 & $-17 \%$ & & & & & \\
\hline$q_{e, 2, w 2}$ & & 0 & 2,093 & 467.1 & 463.5 & $-28 \%$ & $44 \%$ & 207.4 & 23.4 & 443 & 0 \\
\hline$q_{e, 1, w 3}$ & & 76 & 1,415 & 708.1 & 355.7 & $-13 \%$ & & & & & \\
\hline$q_{e, 2, w 3}$ & & 0 & 1,911 & 482.7 & 440.6 & $-25 \%$ & $47 \%$ & 225.4 & 9.7 & 82 & 0 \\
\hline$q_{e, 1, l v}$ & & 49 & 1,392 & 388.9 & 283.1 & $-52 \%$ & & & & & \\
\hline$q_{e, 2, l v}$ & & 0 & 1,862 & 189.1 & 275.2 & $-71 \%$ & $106 \%$ & 199.8 & 52.9 & 867 & 0 \\
\hline$q_{e, 1, s}$ & & 48 & 1,036 & 340.2 & 292.9 & $-58 \%$ & & & & & \\
\hline$q_{e, 2, s}$ & & 0 & 1,111 & 157.8 & 350.6 & $-76 \%$ & $116 \%$ & 182.4 & 18.5 & 158 & 0 \\
\hline$v_{t, 1, d}$ & \multirow{12}{*}{$\frac{\text { F }}{\xi}$} & 80 & 113 & 97.0 & 5.3 & - & & & & & \\
\hline$v_{t, 2, d}$ & & 0 & 155 & 118.5 & 23.3 & - & $-18 \%$ & -21.5 & -104.6 & 13,266 & 0 \\
\hline$v_{t, 1, w 1}$ & & 69 & 111 & 94.7 & 5.8 & $-2 \%$ & & & & & \\
\hline$v_{t, 2, w 1}$ & & 0 & 144 & 113.2 & 25.0 & $-4 \%$ & $-16 \%$ & -18.5 & -44.1 & 3,468 & 0 \\
\hline$v_{t, 1, w 2}$ & & 75 & 105 & 91.7 & 5.4 & $-5 \%$ & & & & & \\
\hline$v_{t, 2, w 2}$ & & 0 & 136 & 107.8 & 27.5 & $-9 \%$ & $-15 \%$ & -16.1 & -12.0 & 443 & 0 \\
\hline$v_{t, 1, w 3}$ & & 81 & 103 & 91.3 & 5.0 & $-6 \%$ & & & & & \\
\hline$v_{t, 2, w 3}$ & & 0 & 131 & 106.5 & 30.8 & $-10 \%$ & $-14 \%$ & -15.2 & -4.4 & 82 & 0 \\
\hline$v_{t, 1, l v}$ & & 61 & 111 & 94.4 & 6.0 & $-3 \%$ & & & & & \\
\hline$v_{t, 2, l v}$ & & 0 & 156 & 105.1 & 38.9 & $-11 \%$ & $-10 \%$ & -10.7 & -7.7 & 867 & 0 \\
\hline$v_{t, 1, s}$ & & 61 & 97 & 70.2 & 8.4 & $-28 \%$ & & & & & \\
\hline$v_{t, 2, s}$ & & 0 & 125 & 82.2 & 13.4 & $-31 \%$ & $-15 \%$ & -12.0 & -19.2 & 158 & 0 \\
\hline$d_{1, d}$ & \multirow{12}{*}{ 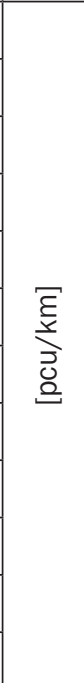 } & 0.5 & 19.7 & 8.6 & 4.1 & - & & & & & \\
\hline$d_{2, d}$ & & 0 & 25.7 & 5.4 & 4.4 & - & $59 \%$ & 3.2 & 168.7 & 13,266 & 0 \\
\hline$d_{1, w 1}$ & & 0.5 & 21.0 & 7.5 & 4.0 & $-13 \%$ & & & & & \\
\hline$d_{2, w 1}$ & & 0 & 24.6 & 4.5 & 4.5 & $-17 \%$ & $67 \%$ & 3.0 & 87.0 & 3,468 & 0 \\
\hline$d_{1, w 2}$ & & 0.9 & 23.2 & 7.6 & 4.4 & $-12 \%$ & & & & & \\
\hline$d_{2, w 2}$ & & 0 & 21.1 & 4.3 & 4.4 & $-20 \%$ & $77 \%$ & 3.3 & 33.8 & 443 & 0 \\
\hline$d_{1, w 3}$ & & 0.8 & 17.0 & 8.0 & 4.0 & $-7 \%$ & & & & & \\
\hline$d_{2, w 3}$ & & 0 & 20.2 & 4.3 & 4.2 & $-20 \%$ & $86 \%$ & 3.7 & 11.3 & 82 & 0 \\
\hline$d_{1, l v}$ & & 0.5 & 15.4 & 4.2 & 2.9 & $-51 \%$ & & & & & \\
\hline$d_{2, l v}$ & & 0 & 16.2 & 1.6 & 2.4 & $-70 \%$ & $163 \%$ & 2.6 & 55.2 & 867 & 0 \\
\hline$d_{1, s}$ & & 0.7 & 17.1 & 5.0 & 6.0 & $-42 \%$ & & & & & \\
\hline$d_{2, s}$ & & 0 & 14.9 & 1.9 & 5.9 & $-65 \%$ & $163 \%$ & 3.1 & 21.9 & 158 & 0 \\
\hline
\end{tabular}


values of dry conditions to wet (rainy) and low visibility conditions (Table $1, \mu_{i, d}-\mu_{i, k}$ ), the mean values are lower for the same lane: mean values of time mean speed from $2 \%$ to $28 \%$ for Lane 1 and $4 \%$ to $31 \%$ for Lane 2. The mean values of density are lower from $13 \%$ to $51 \%$ for Lane 1 and from 7\% to 70\% for Lane 2 .

The boxplots graphs in Figure 2 compare traffic characteristics (equivalent flow rate, time mean speed and density) under different weather conditions, separate for Lane 1 and Lane 2. Each boxplot provides graphical representation of the distribution (dispersion, skewness, and outliers) of the traffic characteristics obtained for test site 178. Particularly for the time mean speed, differences in distribution can be confirmed. In dry weather conditions, there is up to a $27 \%$ difference in the median of time mean speed between Lanes 1 and 2 . In wet conditions, the difference ranges from $24 \%$ to $26 \%$, in low visibility it is up to $23 \%$, and in snow conditions it is up to $12 \%$.

One can observe that in reduced visibility and wet surface conditions traffic flows are lower than in good visibility. This can be explained by the fact that in

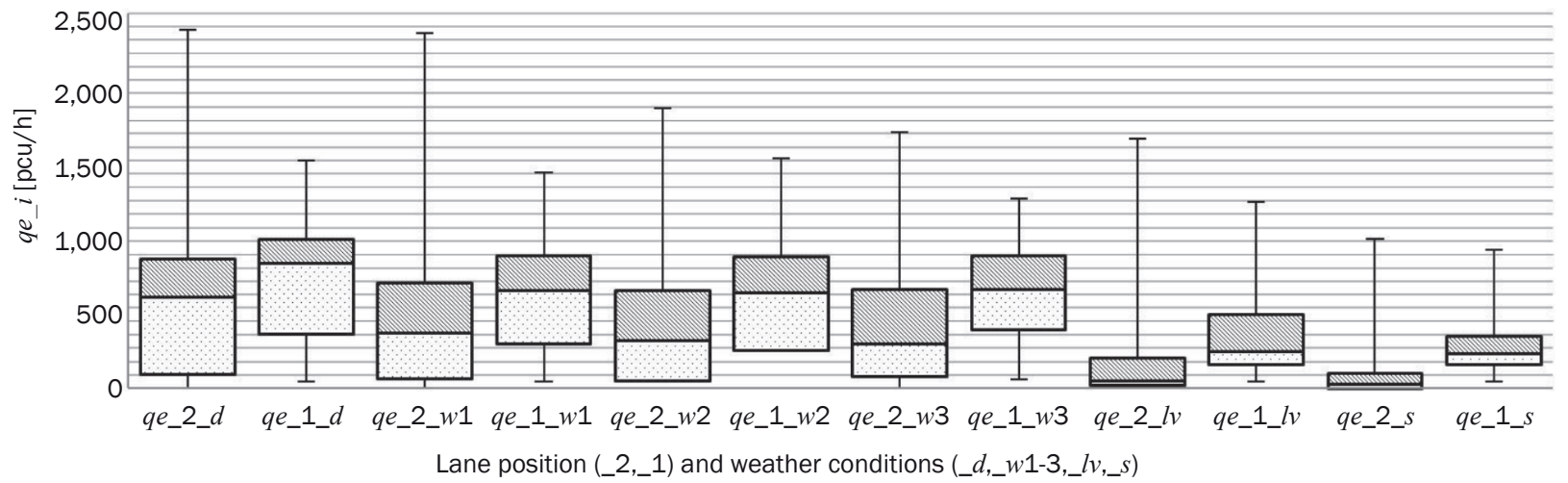

a)

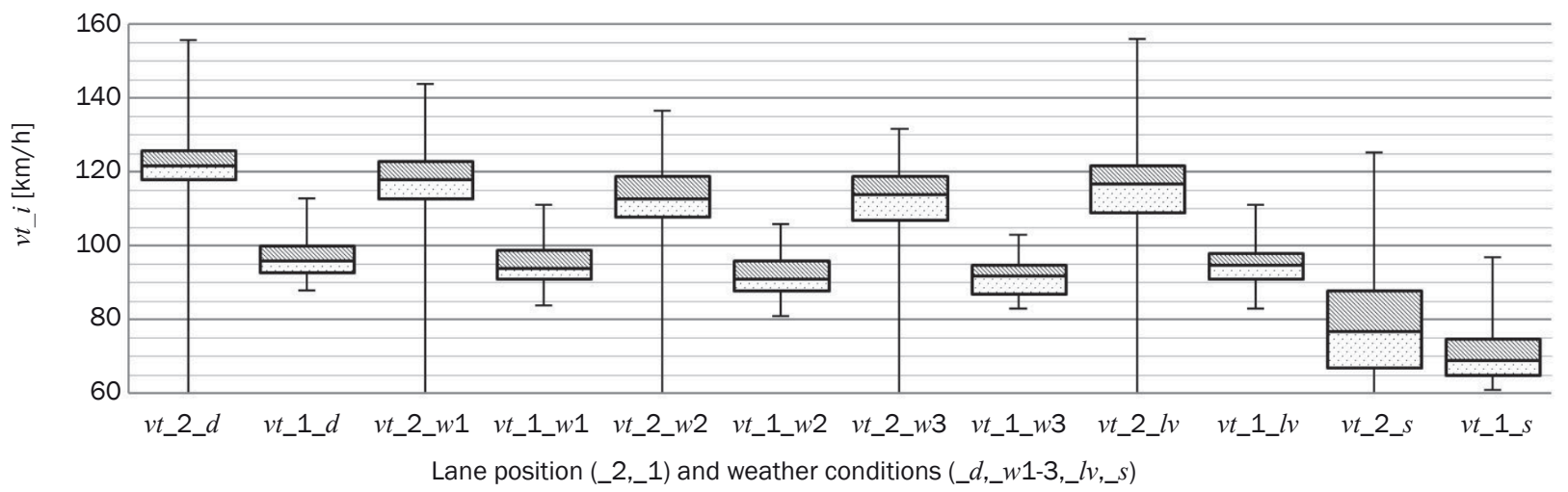

b)

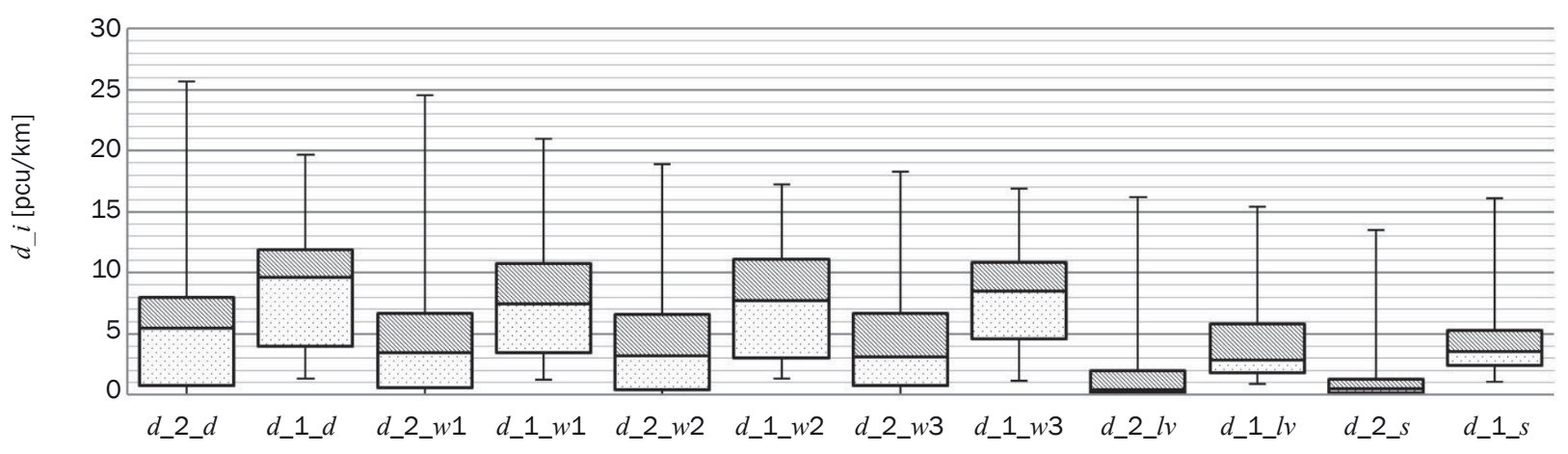

Lane position $\left(\_2, \_1\right)$ and weather conditions $\left(\_d, \_w 1-3, \_l v, \_s\right)$

c)

Figure 2 - Comparison of the a) equivalent flow rate, b) time mean speed, and c) local density, for different lane positions and weather conditions for Site 178 
adverse weather conditions speed is reduced and the distance between vehicles (gap) increases, resulting in a reduction of maximum traffic flow rate and density [29]. The reduction can also be due to other reasons, e.g. fog typically occurs at night or in the early morning, when traffic flows (demand) tend to be low. Nevertheless, the differences in the time mean speed between lanes $\Delta v_{t, k}$ at maximum flow rates under different weather conditions do not change significantly, especially when a high ratio of heavy vehicles is recorded [30]. On the other hand, at maximum flow rates, the differences in local densities $\Delta d_{k}$ vary according to the weather conditions. In good conditions, the density is lower for Lane 1. In intensively wet and snowy conditions, values are lower on Lane 2 . In such conditions, drivers are cautious and usually do not overtake, and consequently, higher capacity utilisation can be achieved. The traffic characteristics for test site 178 for different traffic lanes at maximum flow rates Max $q_{\text {tot }, k}$ for both lanes are summarised in Table 2.

\subsection{Lane flow distributions under different weather conditions}

The lane flow distribution can be explained by traffic demand flow. Graphical illustration of lane flow distribution under different weather conditions consists of $x$-axis presenting total flow rate $q_{t o t, k}$, and $y$-axis presenting lane flow distribution $d p_{k}$, where $d p_{k}=0$ for evenly distributed traffic flow on both lanes, $d p_{k}>0$ for more traffic flow on Lane $1, d p_{k}=1$ for all traffic flow on Lane $1, d p_{k}<0$ for more traffic flow on Lane 2 (overtaking lane), $d p_{k}=-1$ for entire traffic flow on Lane 2. Each event with its own $q_{\text {tot, } k}$ and $d p_{k}$ is represented as an adequate data point (see Figure 3). Graphs depict the phenomena of higher flow on Lane 1 when the total flow rate is low ( $d p_{k}$ near 1.0). When the traffic demand flow increases (including Lane 1), drivers decide to change lanes intensively, seeking faster driving in Lane 2. Taking into account all values in different weather conditions, a regression curve was examined. Different regression models were tested. Best results were obtained using a non-linear models with least squares Levenberg-Marquardt algorithm, where fourth-order (or more) polynomials, exponential, and logarithmic models were tested. Regarding the results the following generalised regression function $d p_{k}\left(q_{t o t, k}\right)$ for a carriageway with two lanes is proposed:

$d p_{k}\left(q_{t o t, k}\right)=a+\frac{b}{1+e^{-c+d \ln q t o t, k}}$

where parameter a generally represents the bottom plateau of the regression curve, $b$ is the range of curve, $c$ is the $q_{\text {tot }, k}$ value when the middle $d p_{k}\left(q_{\text {tot }, k}\right)$ value is attained and $d$ is the slope factor. The lane flow distribution $d p$ can be modelled up to a certain maximum of the traffic flow rate $q_{t o t, k}$, which is somehow representing the capacity of the carriageway under current weather conditions .

The results of the lane flow distribution under different weather conditions and of the regression model for test site 178 are depicted in Figure 3 and summarised in Table 3 . The results for test site 855 are summarised in Table 4.

Tables 3 and 4 present a noticeable difference in the $d p_{k}\left(q_{t o t, k}\right)$ regression models for the observed test sites. However, the impact of weather conditions on lane flow distribution is very similar. In contrast to site 178 , where there is more transit traffic and higher ratio of heavy vehicles, at site 855 there is more local and regional traffic.

The rate of change (slope) of the $d p_{k}\left(q_{t o t, k}\right)$ function is not the same for different weather conditions. This can be explained as differences in lane-changing manoeuvres under different weather conditions; at very high (but still uncongested) traffic flows $d p_{k}$ values converge to -0.3 in dry $\left(\_d\right)$ and in low rainfall intensity $\left(\_w 1\right)$, to -0.175 in medium rainfall intensity (_w2), to 0.165 in heavy rain (_w3), to -0.135 in low visibility

Table 2 - Main traffic characteristics at maximum total flow rate under different weather conditions for test site 178

\begin{tabular}{|c|c|c|c|c|c|c|c|}
\hline \multirow{2}{*}{$\begin{array}{c}\text { TFC } \\
\text { at } \operatorname{Max} q_{t o t, k}\end{array}$} & \multirow{2}{*}{ Units } & \multicolumn{6}{|c|}{ Weather conditions } \\
\hline & & $d$ & $\_w 1$ & $\_w 2$ & $\_w 3$ & _lv & $\_s$ \\
\hline $\operatorname{Max} q_{t o t, k}$ & {$[\mathrm{pcu} / \mathrm{h}]$} & 4,285 & 4,223 & 3,661 & 3,272 & 3,254 & 2,102 \\
\hline$q_{e, 1, k}$ & \multirow{3}{*}[\mathrm{pcu}/\mathrm{h}]{} & 1,610 & 1,574 & 1,711 & 1,407 & 1,392 & 991 \\
\hline$q_{e, 2, k}$ & & 2,675 & 2,649 & 1,950 & 1,865 & 1,862 & 1,111 \\
\hline$\Delta q_{e, k}$ & & $-1,065$ & $-1,075$ & -239 & -458 & -470 & -120 \\
\hline$v_{t, 1, k}$ & \multirow{3}{*}[\mathrm{km}/\mathrm{h}]{} & 87 & 92 & 75 & 89 & 92 & 68 \\
\hline$v_{t, 2, k}$ & & 107 & 108 & 93 & 105 & 115 & 85 \\
\hline$\Delta v_{t, v}$ & & -20 & -16 & -18 & -16 & -23 & -17 \\
\hline$d_{1, k}$ & \multirow{3}{*}[\mathrm{pcu}/\mathrm{km}]{} & 18.7 & 17.2 & 23.2 & 17.8 & 15.2 & 14.9 \\
\hline$d_{2, k}$ & & 25.1 & 24.6 & 21.1 & 15.9 & 16.2 & 13.2 \\
\hline$\Delta d_{k}$ & & -6.4 & -7.4 & 2.1 & 1.9 & -1 & 1,7 \\
\hline
\end{tabular}


Table 3 - Results of dp regression model for test site 178

\begin{tabular}{|c|c|c|c|c|c|c|}
\hline \multirow{2}{*}{ Weather condition } & \multicolumn{4}{|c|}{ Parameter } & \multirow{2}{*}{$q_{t o t, k}$ at $d p=0$} & \multirow{2}{*}{$\mathrm{R}^{2}$} \\
\hline & $a$ & $b$ & $c$ & $d$ & & \\
\hline $\operatorname{Dry}\left(\_d\right)$ & -0.927 & 1.987 & 6.383 & 0.836 & 2,430 & 0.917 \\
\hline Low rainfall (_w1) & -1.622 & 2.832 & 5.082 & 0.618 & 2,310 & 0.898 \\
\hline Medium rainfall (_w2) & -2.329 & 3.733 & 4.245 & 0.480 & 2,438 & 0.915 \\
\hline Heavy rainfall (_w3) & -2.590 & 3.866 & 5.020 & 0.555 & 2,356 & 0.915 \\
\hline Low visibility $\left(\_l v\right)$ & -0.620 & 1.611 & 6.987 & 0.966 & 2,251 & 0.776 \\
\hline Snow conditions $\left(\_s\right)$ & -0.462 & 1.445 & 8.632 & 1.242 & 1,915 & 0.744 \\
\hline
\end{tabular}
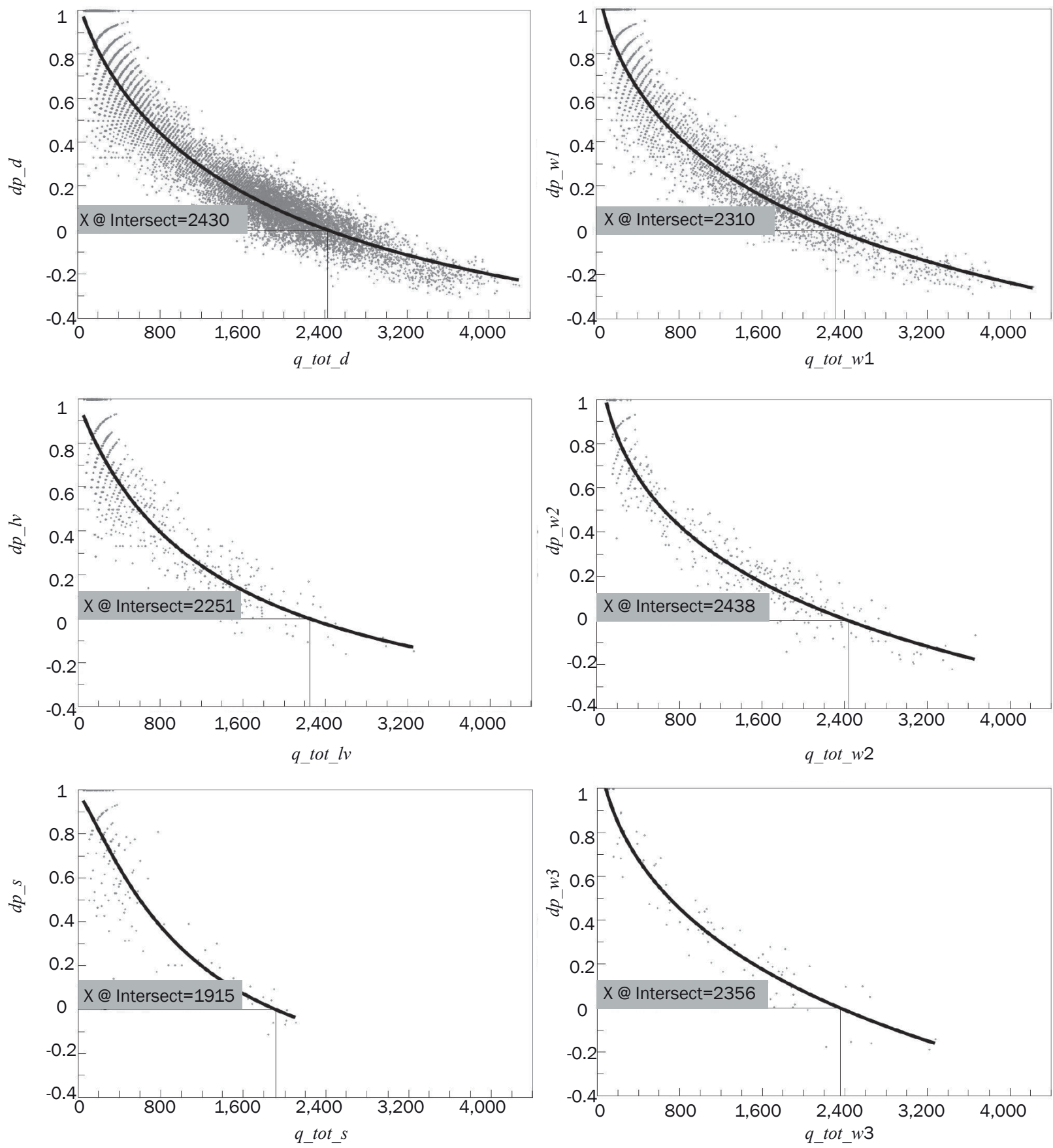

Figure 3 - Lane flow distributions on site 178 under different weather conditions 
Table 4 - Results of $d p$ regression model for test site 855

\begin{tabular}{|c|c|c|c|c|c|c|}
\hline \multirow{2}{*}{ Weather condition } & \multicolumn{4}{|c|}{ Parameter } & \multirow{2}{*}{$q_{t o t, k}$ at $d p=0$} & \multirow{2}{*}{$\mathrm{R}^{2}$} \\
\hline & $a$ & $b$ & $c$ & $d$ & & \\
\hline $\operatorname{Dry}\left(\_d\right)$ & -0.499 & 1.417 & 8.122 & 1.087 & 3,084 & 0.905 \\
\hline Low rainfall $\left(\_w 1\right)$ & -0.683 & 1.646 & 7.287 & 0.953 & 3,009 & 0.878 \\
\hline Medium rainfall ( _w2) & -1.139 & 2.056 & 7.064 & 0.854 & 3,032 & 0.845 \\
\hline Heavy rainfall $\left(\_w 3\right)$ & -0.714 & 1.582 & 7.808 & 0.989 & $>2,983 *$ & 0.821 \\
\hline Low visibility $\left(\_l v\right)$ & -1.316 & 2.314 & 6.486 & 0.784 & 2,737 & 0.737 \\
\hline Snow conditions $\left(\_s\right)$ & -2.596 & 3.527 & 10.963 & 1.319 & $>1,520 *$ & 0.497 \\
\hline
\end{tabular}

*: $d p \leq 0$ was not reached

$\left(\_l v\right)$, and to -0.075 in snow $\left(\_s\right)$ conditions. Note, that negative values of lane flow distribution correspond to higher traffic flow on Lane 2.

Negative values of lane flow distribution can indicate the disturbances in uncongested traffic flow. At a given traffic demand flow and speed variability, drivers change lanes with more difficulty, indicating the potential for traffic congestion and accidents [27]. The results in Figure 3 show that this phenomenon occurs earlier in adverse weather conditions, especially those that have a significant impact on the decisions of the drivers to change lanes. In the case of test site 178 snow has the most significant effect. Rainfall affects lane choice less, despite the fact that sight distance is reduced and road slipperiness is increased. Note that because of blinding spray the real sight distances during rainfall are shorter than those recorded by the weather station; therefore, the results do not necessarily reflect the state of visibility during precipitation. Therefore, additional studies are required on different types of weather stations or methods for on-board visibility distance measurements.

\subsection{Lane speed and average gap variations under different weather conditions}

The lane speed variations (expressed by a standard deviation or CVS) and the minimum average gap are the main indicators representing the relationship between road safety and motorway traffic

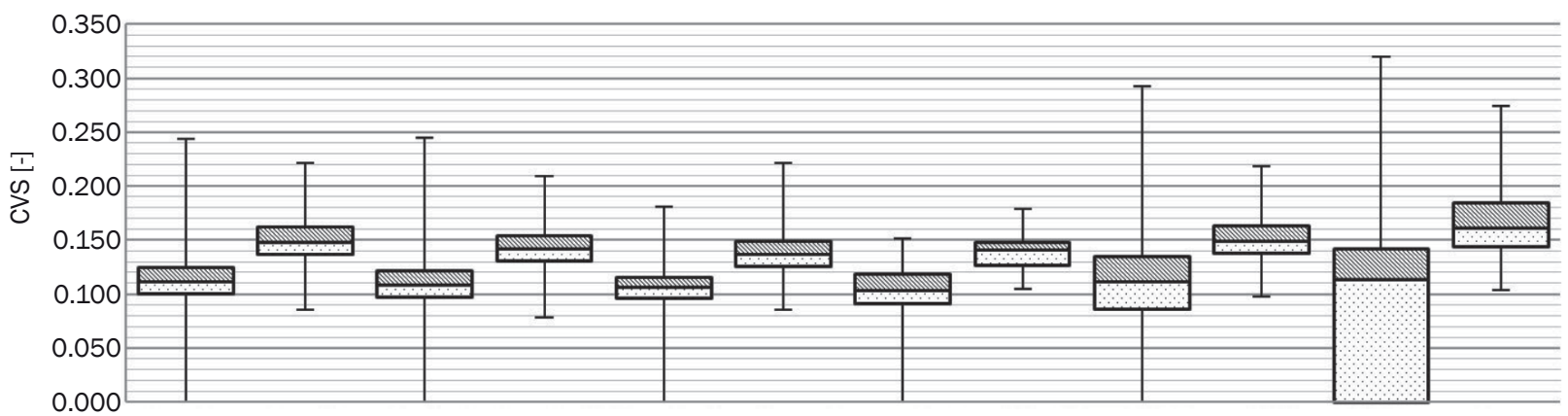

CVS_2_d CVS_1_d CVS_2_w1CVS_1_w1CVS_2_w2CVS_1_w2CVS_2_w3CVS_1_w3 CVS_2_lv CVS_1_lv CVS_2_s CVS_1_s Lane position $\left(\_2, \_1\right)$ and weather conditions $\left(\_d, \_w 1-3, \_l v, \_s\right)$

a)

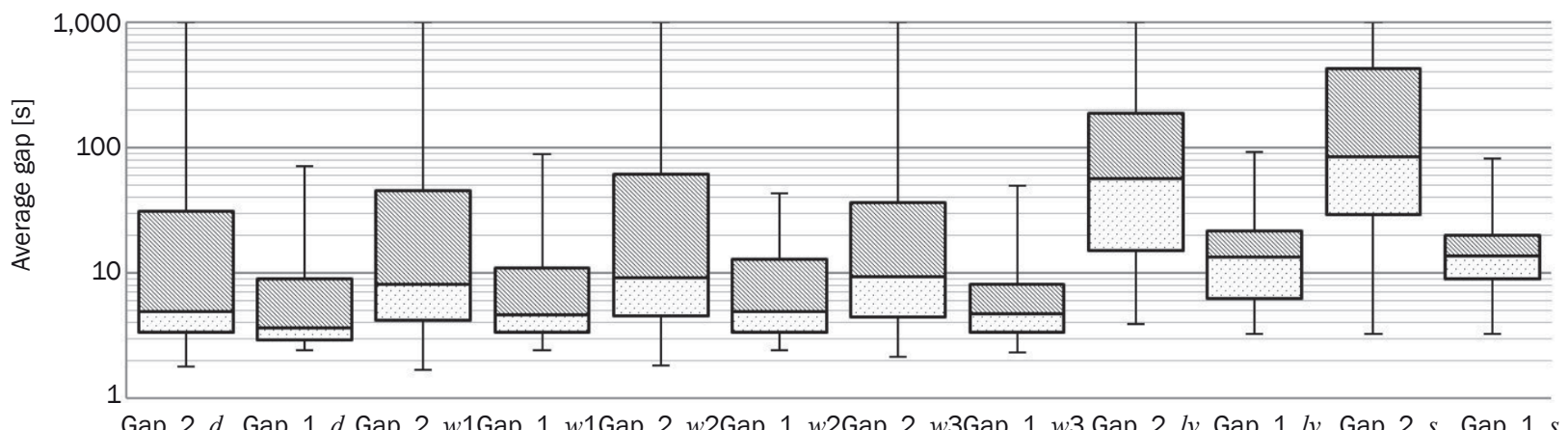

Gap_2_d Gap_1_d Gap_2_w1Gap_1_w1Gap_2_w2Gap_1_w2Gap_2_w3Gap_1_w3 Gap_2_lv Gap_1_lv Gap_2_s Gap_1_s Lane position $\left(\_2, \_1\right)$ and weather conditions $\left(\_d, \_w 1-3, \_l v, \_s\right)$

b)

Figure 4 - Comparison of a) CVS values, and b) average gap for different lane positions and weather conditions for site 178 
characteristics [20]. Figure 4 presents the CVS values and 5-minute average gaps under different weather conditions at site 178 .

A visual comparison of the boxplots shows that the median value of CVS in all weather conditions is higher on Lane 1, but the maximal value is higher on Lane 2 for dry, low rainfall intensity, low visibility, and snow conditions (Figure 4a). In general, CVS dispersion is the highest in snow, followed by low visibility conditions, low rainfall intensity, and dry conditions. This cannot be linked to the fact that the vast majority of weather-related crashes happen on dry or wet pavement during rainfall. We can link this fact to exposure to events with different weather conditions. However, it can be assumed that drivers act more rationally in high and medium intensity rainfall. On the other hand, many severe motorway accidents in Slovenian history have been connected with adverse weather conditions, particularly low visibility and snowy conditions.

The dispersion of average gaps is higher on Lane 2 , irrespective of weather conditions (Figure $4 b$ ). Both lanes have a very similar minimal average gap for all types of weather conditions. Lower values are generally representative of Lane 2 (dry and wet conditions). As expected, the median, the $3^{\text {rd }}$ quartile, and maximum values of average gaps are higher on Lane 2 for all weather conditions.

\section{CONCLUSIONS}

In this paper, the influence of weather conditions has been investigated. In particular, the focus is on the lane flow distribution on motorway; traffic flow characteristics observed for different traffic lanes and the choice of the traffic lane. Normal weather conditions (dry, no precipitation, and good visibility), rainy conditions (low, medium, and heavy intensity), very low visibility (less than $250 \mathrm{~m}$ ), and snowfall conditions were analysed. Most papers on lane flow distribution neglect weather conditions. According to Lee and Park [29], traffic flow rate cannot properly identify traffic conditions, since one traffic flow rate corresponds to two mean speeds, namely in uncongested and congested traffic conditions. In our study only data in uncongested-to-transition traffic flow were considered; incident and congested conditions were filtered out.

In this paper, the empirical research results confirm the hypothesis that traffic flow characteristics are influenced by different weather conditions, and the influence is not the same for all traffic lanes at the same test site. In adverse weather conditions, the time mean speed, traffic flow rates, and density are reduced, and at the same time, the average gap between vehicles increases and diversity between lanes is observed. This indicates that weather conditions influence lane flow and speed distributions on motorway sections with the same geometric characteristics, traffic, and operational conditions. Furthermore, CVS values in conditions with lower visibility (fog, heavy snowfall) are more dispersed than in conditions with normal visibility at the same site. These findings can result in the redefinition of criteria (or use of additional criteria) for active traffic control in the case of disturbance in uncongested traffic flow and different weather conditions which depends on speed variability and traffic flow rate on Lane 2 (overtaking lane). In this way, it is also indicated that through observations and short-term weather forecasting, it is possible to predict lane flow distribution for a given traffic demand flow.

In previous studies, lane flow distribution models were defined only for specific and similar geolocations. Accordingly, future research can continue in the direction of determining a set of pattern conditions that influence lane flow and speed distribution. In this manner, it is possible to examine whether the estimated models from one site can be applied to other sites with similar roadway characteristics, traffic-operational rules, and environmental conditions. Studies should also include new pavement technology (that ensures faster drainage of surface water and reduce blinding spray) and extreme and micro-located weather conditions (e.g. very dense fog, unexpected heavy storms, hailstorms, and storms with strong wind gusts). On road sections with higher ratio of heavy vehicles or with higher longitudinal road slope (additional lane for slow-moving vehicles) incidents are more likely to occur; therefore, the focus should be also on such sections.

mag. ROBERT RIJAVEC ${ }^{1}$

E-mail: robert.rijavec@fgg.uni-lj.si

dr. DARJA ŠEMROV ${ }^{1}$

E-mail: darja.semrov@fgg.uni-lj.si

1 Univerza v Ljubljani,

Fakulteta za gradbeništvo in geodezijo

Jamova 2, 1000 Ljubljana, Slovenija

\section{VPLIV VREMENSKIH POJAVOV NA PORAZDELITEV PROMETNEGA TOKA PO PROMETNIH PASOVIH NA AVTOCESTI}

\section{POVZETEK}

Na avtocestah vozniki izbirajo prometne pasove v odvisnosti od različnih dejavnikov. Skladno s pravili vožnje najpogosteje izberejo desni prometni pas, levega pa uporabijo za prehitevanje, v primeru zastojev, ovir in drugih omejitev na voznem pasu. Empirična raziskava predstavljena $v$ tem članku obsega obsežno analizo karakteristik prometnega toka na različnih prometnih pasovih avtocest v Sloveniji. Poudarek raziskave je na vplivu neugodnih vremenskih razmer na porazdelitev prometnih obremenitev po prometnih pasovih in na porazdelitev hitrosti vozil na posameznem prometnem pasu ter po pasovih. Poznavanje teh karakteristik ima neposreden vpliv na poznavanje pretočnosti in prometne varnosti, zato s pravilno oceno lahko izboljšamo zanesljivost vodenja prometa $v$ realnem času ob pojava nemira $v$ prometnem toku. Rezultati analiz 
dokazujejo, da se porazdelitev prometnih tokov in porazdelitev hitrosti na posameznem pasu specifičnega avtocestnega odseka spreminjajo $v$ odvisnosti od vremenskih pojavov, ki smo jih imenovali suho, mokro (dež), slaba vidljivost ter sneženje.

\section{KLJUČNE BESEDE}

nadzor in vodenje prometa na avtocesti; porazdelitev prometa po pasovih; porazdelitev hitrosti po pasovih; vremenski pojavi;

\section{REFERENCES}

[1] HCM 2010: Highway capacity manual. Fifth edition. Washington, D.C.: Transportation Research Board; 2010.

[2] Calvert SC, Snelder M. Influence of rain on motorway road capacity - A data-driven analysis. In: Proceedings of the $16^{\text {th }}$ International IEEE Conference on Intelligent Transportation Systems (ITSC 2013); 2013.

[3] Weng J, Liu L, Rong J. Impacts of Snowy Weather Conditions on Expressway Traffic Flow Characteristics. Discrete Dynamics in Nature and Society. 2013;2013: 6p.

[4] Aaheim HA, Hauge KE. Impacts of climate change on travel habits - A national assessment based on individual choices. CICERO Report 2005:07, 2005. Available from: https://brage.bibsys.no/xmlui/bitstream/ handle/11250/191992/CICERO_Report_2005-07. pdf?sequence=1\&isAllowed=y [cited Mar 24 ${ }^{\text {th }}$ 2017].

[5] Grabec I, Kalcher K, Švegl F. Modeling and Forecasting of Traffic Flow. Nonlinear Phenom Complex Syst. 2010;13(1): 53-63.

[6] Knoop VL, Duret A, Buisson C, Van Arem B. Lane distribution of traffic near merging zones influence of variable speed limits. In: Proceedings of the $13^{\text {th }}$ International IEEE Conference on Intelligent Transportation Systems; 2010.

[7] Hoseini SMS. Comparison of microscopic drivers' probabilistic lane-changing models with real traffic microscopic data. Promet - Traffic \& Transportation. 2011;23(4): 241-251.

[8] Wall G, Hounsell N. Microscopic modelling of motorway diverges. European Journal of Transport and Infrastructure Research. 2005;5(3): 139-58.

[9] Pompigna A, Rupi F. Differences between HCM procedures and fundamental diagram calibration for operational loss assessment on Italian freeways. Transportation Research Procedia. 2015;5: 103-118.

[10] Li L, Wang F-Y. The automated lane-changing model of intelligent vehicle highway systems. In: Proceedings of the IEEE $5^{\text {th }}$ International Conference on Intelligent Transportation Systems; 2002.

[11] Wu N. Impact of traffic regulation on lane flow - distribution and capacity of motorways. In: Proceedings of the $5^{\text {th }}$ International Conference of Transportation Professionals, At Xian, China; 2005.

[12] Daganzo CF. A behavioural theory of multi-lane traffic flow. Part I: Long homogeneous freeway sections. Transportation Research Part B: Methodological. 2002;36(2): 131-158.

[13] Wu N. Equilibrium of Lane Flow Distribution on Motorways. Transportation Research Record: Journal of the Transportation Research Board. 2006;1965: 48-59.

[14] Heidemann D. Distribution of traffic to the individual lanes on multilane unidirectional roadways. In: Proceedings of the second international symposium on highway capacity; 1994.
[15] Ibrahim AT, Hall FL. Effect of adverse weather conditions on speed - flow occupancy relationships. Transportation Research Record. 1994;1457: 184-191.

[16] Billot R. Weather Impacts on Traffic: From Data to Models [presentation]. In: COST Final Seminar, Helsinki; 2011. Available from: http://www.sirwec2012.fi/Cost/ S4_2A_Billot.pdf [cited 2017 Mar 24].

[17] Hablas H. A Study of Inclement Weather Impacts on Freeway Free-Flow Speed. Master Thesis. Faculty of the Virginia Polytechnic Institute, Virginia; 2007. Available from: https://theses.lib.vt.edu/theses/available/ etd-07032007-102318/unrestricted/Hablas.pdf [cited 2017 Mar 24].

[18] Agarwal M, Maze TH, Souleyrette R. Impacts of Weather on Urban Freeway Traffic Flow Characteristics and Facility Capacity. In: Proceedings of the 2005 Mid-Continent Transportation Research Symposium; 2005. Available from: http://www.ctre.iastate.edu/pubs/midcon2005/ AgarwalWeather.pdf [cited 2017 Mar 24].

[19] Kompan R. Vpliv hitrosti vozil na prometno varnost pri različni intenziteti dežnih padavin. Graduation Thesis. Faculty of Faculty of Maritime Studies and Transport, Portorož; 2010.

[20] Golob TF, Recker W, Pavlis Y. Probabilistic models of freeway safety performance using traffic flow data as predictors. Safety Science. 2008;46(9): 1306-1333.

[21] Lee C, Hellinga B, Saccomanno F. Real-Time Crash Prediction Model for Application to Crash Prevention in Freeway Traffic. Transportation Research Record: Journal of the Transportation Research Board. 2003;1840: 67-77.

[22] Abdel-Aty M, Pande A. Identifying crash propensity using specific traffic speed conditions. Journal of Safety Research. 2005;36(1): 97-108.

[23] Zorin U, Rijavec R, Pirc J, Gostiša B, Gorup S. Functional ITS on Slovenian motorways. In: Proceedings of ITS World Congress; 2012.

[24] Strnad I, Kramar Fijavž M, Žura M. Numerical optimal control method for shockwaves reduction at stationary bottlenecks. Journal of advanced transportation. 2016;50(5): 841-856.

[25] DARS d.d. Smernice za sistem nadzora in vodenja prometa na avtocestah v RS; 2004.

[26] Christian R, Maximilan L, Dietmar B, Roland A, Werner $\mathrm{B}, \mathrm{Knud} \mathrm{K}$. Influence of weather on transport demand: a case study from the Vienna region. Transportation Research Record: Journal of the Transportation Research Board. 2015;2482.

[27] Xiao C, Shao C, Meng M, Wang P, Wang B. Lane Flow Distribution of a Long Continuous Highway. European Transport. 2014. Available from: http://www.istiee. org/te/papers/N56/P06_56_12_2014.pdf [cited 2017 Mar 24].

[28] Drake JS, Schofer JL, May AD. A Statistical Analysis of Speed Density Hypotheses. Highway Research Record. 1967;(154): 53-87.

[29] Lee J, Park BB. Determining Lane Use Distributions Using Basic Freeway Segment Density Measures. Journal of Transportation Engineering. 2012;138(2): 210-217.

[30] Faheem H, Hashim IH. Analysis of Traffic Characteristics at Multi-lane Divided Highways, Case Study from Cairo-Aswan Agriculture Highway. International Refereed Journal of Engineering and Science. 2014;3(1): 58-65. 